\title{
Beijing Olympics: a New Brand of China
}

\author{
$\mathrm{Te} \mathrm{Bu}$ \\ Graduate School \\ Beijing Sport University \\ Beijing 100084, China \\ E-mail: buteagu@sina.com
}

\begin{abstract}
The article analyzes Beijing Olympic brand value from the dimension of nation, cities, enterprises and citizens. The author holds the view that, the nation displays in the Beijing Olympic Games the brand value of harmony, confidence and tolerance; cities convey the brand value of tradition, modern, and green; enterprises market the brand value of independence, quality, and value; citizens express the brand value of civilization, passion and smile. The brand value of Beijing Olympic Games is a significant part of the Olympic spiritual heritage and research on it will have a positive effect on spiritual civilization construction.
\end{abstract}

Keywords: National brand, City brand, Enterprise brand, Citizen brand

On August $1^{\text {st }}, 2008$, in the interview with Chinese and foreign reporters in the great hall of peoples, the Chinese President Hu Jintao pointed out, "hosting of the Beijing Olympic Games will leave behind a set of sports stadiums and infrastructures for us. We cherish very much these tangible heritages, and will fully explore their functions and significance. Meanwhile, we realize that, the spiritual heritage of Beijing Olympic Games will be more permanent and invaluable." Among the spiritual heritage series of Beijing Olympic Games, the heritage of brand value is "the most permanent and invaluable". A brand is a kind of language readable to people in the whole world, and China as a growing up country, should enable whole world to understand it. On the best platform of Beijing Olympic Games, China displays to the whole world its national image, city enchantment, enterprise force and citizen making. This article systematically studies Chinese brand built up by Beijing Olympic Games from the dimension of nation, cities, enterprises and citizens, excavates historical value of Beijing Olympic Games, and deeply surveys "Green Contribution" made by sports to social development. The Beijing Olympic Games will not only change history of international Olympic Games, but also is altering international path of China. Therefore, how to protect and manage the brand value of Beijing Olympic Games is a topic with both realistic significance and long-term strategic significance.

\section{National brand}

In recent years, growing up of China has been a phenomenon extensively concentrated by the international society. Meanwhile, such misunderstandings and prejudices as "theory of china threat" have also appeared accordingly. Under such a circumstance, how to effectively manage the national image of China and how to enable China to gain the respect of the whole world while being concentrated has also been an important topic in the process of its peaceful growing up. The 2008 Beijing Olympic Games is exactly an important opportunity to upgrade the national image. The highest level of Olympic marketing is to successfully market a country, while the marketing of a country is to set up the image and status of a country internationally, which is also a process of displaying the national brand. The national image refers to the overall assessment of the international society and public on the stability of the country. National image is not an entity, but a symbol and a sign. It is constituted by several factors, such as the geographic surroundings of a country, its internal and external policies, its development conditions, its cultural features, and its national spiritual styles, etc,. The national image is affected both by hard strength and by soft strength of a country. The former refers to specific measurable resources and rights, including population, territory, natural resources, economic power, military power, social power, and rights and influences in the international affairs. While the latter refers to cultural appeal and political values. The latter is the constructive foundation of the national image, which attracts and affects others with its internal vigor and enchantment, and which is more permanent and effective.

In the history of modern Olympic Games, America has held Olympic Games for 8 times and has promoted its national 
brand and culture to the greatest extent. However, the international society generally believes that, it is South Korea that has most successfully marketed the national brand by holding the Olympic Games. Beijing Olympic Games is the best stage to display Chinese national image, and is the most important opportunity to market its national brand. Since the reform and opening up, China has successfully finished its great historical transition, and realized rapid economic and social development. Its GDP has increased from 364.5 billion RMB to 22.66 trillion RMB, its economic gross has sprung up to the fourth in the world, and its comprehensive national strength has increased continually. In these 30 years, historical changes have taken place to the visage of Chinese people, to the influences of the socialist China, and to the status of Communist Party of China. Through display of these historical changes, the whole world is appreciating the civilized and open national image of Chinese democratic advancement. We regard the period from the reform and opening up to the entrance into WTO as the first phase of China going towards the international stage. Successful hosting of the Beijing Olympics, and important role of China in this financial tsunami prove that China has entered the second phase of developing its national image and building up the Chinese brand. The series of national brand value displayed in the Beijing Olympic Games is as follows:

\subsection{Harmony}

Harmony is the primary tone of Beijing Olympic Games. When displaying well-rounded culture of the world, Beijing is also exhibiting harmony of Chinese culture and profound details of Chinese civilization to the whole world. The ideal of "technology empowered Olympics, culture enriched Olympics, environment friendly Olympics" contained in the harmonious, and esthetical harmony, pursuit of "One World, One Dream", and perfect complement for the sports culture of Olympic Games --"Higher, Swifter, Stronger" are exploitation and development of Olympic spirit. The long-standing Chinese civilization will also creatively realize communication and integration with Olympic culture, and will implant new connotations for "Peace, Friendship, Progress". China has fulfilled its commitment towards International Olympic Committee out and out, Beijing Olympic Games has been held orderly and the Chinese people have behaved perfectly, which altogether leave an overall impression upon the world: a peaceful China, a civilized China, and a progressive China. China in such a condition is not frightening, but on the contrary, it is affable and harmonious. "The world will finally go towards progress and brightness. Success of Beijing Olympic Games is not only owing to China, but to the whole world."

\subsection{Confidence}

Chinese people were called "Sickman of East Asia" before its liberation; in old China, the Olympic Games was "One Man's Olympics"; the reform and opening up of China broke through the history of the number zero in the total number of golden medals; in the new century, an Olympics with "high quality and special features" was held, in which China won the most golden medals among all countries; all these facts prove that, such rapid development of Chinese sports cause has gained stronger confidence in Chinese people. Before and after Beijing Olympics was held, never stopped negative information about China by western media, their critical reports, and their comments of resisting Beijing Olympics. In face of all kinds of doubt, arraignment, and unfriendliness, no blame or complaint has been manifested whether in leaders of the country or in its common citizens. Instead, they confront all with an attitude of understanding, tolerance and gentleness all along. They have tolerated all with their broad bosom, they transfer all misunderstandings into trust with lots of indisputable facts, and they change arraignment into high praise. Chinese peoples' tolerance, their open mind, and their diversified voices are all harvests from the Beijing Olympics. Of course, all these harvests can be summarized as indication of a more confident country. That is, what we have gained from the Beijing Olympics is confidence of the Chinese people.

At the time when China is recognized by the international society, it is inevitable that it will endure much exclusion and doubt, and conflicts of ideology and culture. Western countries never doubt whether China has the competence to hold the Olympics, but they doubt about validity of it holding the Olympics. It can't be denied that, there has stronger central consciousness of western discourse. In evaluation of various activities of the Beijing Olympics, it is natural that they measure all with the western standard. Chinese people regard the "collision of different thinking modes" as a process of learning, perfection and growing, and they further achieve self-identity and self-expression in the process of conflicting communication, so as to confirm the future status in the international society. Therefore, "in order to maintain and display a perfect national image, we should listen to and accept different voices leisurely with an attitude of tolerance, promote cross-cultural communication frankly, and see it as motive for sustainable development and progress. Meanwhile, Chinese people are undergoing self-check and reflection on "the national characteristics", For example, Du Li missed the first golden medal of the Olympics, Lang Ping led American female volleyball team to defeat the Chinese team, the Flying Man Liu Xiang suddenly withdrew from the contest --- in face of these facts, the majority of Chinese people acted with an attitude of tolerance and understanding, which has won praise and respect from the whole world.

The Beijing Olympics takes advantage of all sorts of paths to introduce to the whole world ancient and civilized Chinese culture, to display the positive spirit and social life of its people, to declare the spiritual essence and key elements in its national image, to affect or change western countries' long-time opinions and views on the outdated conditions of Chinese people, and to elevate the overall national image and brand. 


\section{City brand}

"In 1970s, politicians, entrepreneurs, and other interest-related parties regarded sports as a tool for elevating the image and appeal of a city, especially of a region. According to them, sport was one of the few means to figure the image of a city." In the current society of globalization and commercialization, impacts of Olympics on the society increases day by day. Accordingly, the city government gradually realized that, they could acquire potential interests from organizing and holding an Olympics, and World Cup, etc,. Of course, sports contest can be an effective tool for realizing administrative target of a city. For instance, city brands of some European countries, such as Barcelona, Rotterdam, and Turin are all world-famous because of their sports contest. Therefore, "Success or failure of an Olympics does not depend on its temporary gain or loss, but on the long-term development of the host city. Without the Montreal Olympics in 1976, its current development would not be possible." With the three major ideals of "environment friendly Olympics, technology empowered Olympics, culture enriched Olympics," Beijing quickens its construction, upgrades its overall development level, greatly promotes its city brand, displays its city enchantment, and is, therefore, highly praised by oversea guests. The city brand value conveyed in the Beijing Olympics is as follows:

\subsection{Tradition}

The Beijing Olympics is a great combination of the Olympics with a history of 100 years and the Chinese civilization with a history of 5000 years, a grand gather of culture from all over the world and the Chinese culture, a passionate talk between the Eastern civilization and Western civilization, and will become a window for mutual understanding of China and the world. Chinese elements have displayed their particular enchantment in the long cultural corridor of Olympics. For example, the Olympic badge "Chinese stamp, dancing BJ", the Official Mascots "Friendlies", the torch "Auspicious Cloud", and the golden medal "Gold and jade" all perfectly integrate Chinese culture with the Olympic Spirit. Chinese people have revealed extreme passion towards the Olympics. The crowded torch relay, the Olympic slogan everywhere, and Olympic tickets sold out once--- the ancient and traditional Beijing has been implanted with adolescent energy, and an Olympic atmosphere can be felt everywhere.

\subsection{Modern}

The stadium design and construction of Beijing Olympics has become a nonesuch of a harmonious combination of history, culture and nature. From the perspective of city development, Asian games realized the route from central axis to North 4th Ring, while Olympics has realized the extension of the central axis from North 4th Ring to North 5th Ring --- such Olympic facilities as the national stadium, and Olympic Forest Park have enabled the central axis to pass across Olympic Center and to extend towards north. An overlook at the central axis after extension, it is in the shape of a dragon constituted by a water system. The Olympic Forest Park also constitutes a water system sight of central axis together with the original six seawater systems, which altogether form an open ending of central axis centered with natural virescence. All this makes such Olympic building complex as the Bird's Nest and Water Cube introjected into the historical and modern Beijing, and into the natural virescence and cultural virescence. Total investment amount for the Beijing Olympic infrastructure was 280 billion RMB, the total investment amount for the stadium construction was 13 billion RMB, and total running capital was approximately 14 billion RMB. In 2001, the length of subway route in Beijing was only 54 kilometers, while by July 2008, the total course of its traffic had reached 200 kilometers. The newly built expressway, new airline station building at the airport, environmental control and environmental protection investment, and informationization establishment all have obviously improved infrastructure and service level in Beijing. A modernized Beijing is exhibited to the whole world.

\subsection{Green}

Beijing Olympic stadiums are all "Green Buildings". According to incomplete statistics, environmental protection projects adopted in the whole Olympic projects approximated over 190. Merely in the construction of Olympic Village and the National Stadium, 36 and 26 advanced technologies were respectively integrated and applied. In the Olympic Village, regenerative water heat pump system was applied for the first time, which could save 60 million kilowatt-hour each year. The adoption of advanced sewage treatment has enabled regenerative use rate of the sewage treatment in Olympic stadiums to reach $100 \%$. Such tough measures as capital stee relocation, channel sedimentation clearance, energy saving and drainage reduction, etc, have regained Beijing the green water and blue sky. Forests in the whole city covers approximately $50 \%$, and those in mountainous areas attain $70 \%$. Both sides of "the Five Rivers and Ten Routes" have been lined with a virescence belt of 23,000 hectares, and urban districts have been lined with a virescence insulation belt of 12,000 hectares. Three green ecological screens have been almost completed, and virescence coverage rate in the city has exceeded $40 \%$. Besides, the number of days when the quality of the air is above Grade Two has been increased from the original $50 \%$ to the current $70 \%$. Therefore, it can be said that Beijing has realized its "Green Commitment".

Olympics is not only a sports game, but an economic game, which can promote rapid growth of a hosting city. However, afterwards, long-term demand driven by expansion of investment demand dramatically shrinks, and the rapidly 
improved economy descends due to loss of motive, which is the normally named "Post-Olympic risk". In 1999 after the Nagano winter Olympics, its manufacturing industry descended by 30\%, and 211 enterprises went bankrupt, in which Nagano underwent a pain of "Post-Olympic syndrome. The claimed most successful Olympics in the history --- Sydney also didn't escape from the "Post-Olympic risk". And even more seriously, the Athens Olympics in 2004 suffered a lumbersome "Post-Olympic risk". Beijing Olympics is the first Olympics held by developing countries. Whether from the perspective of Chinese economy, or from the perspective of Chinese development speed and the city construction space, Beijing is completely capable of avoiding "Post-Olympic risk". However, the American "Financial Crisis" after Beijing Olympics has swept the global economy, which inevitably is affecting reversely Chinese economy. In order to keep the economic development speed, the Chinese government has adopted a series of tough measures to enlarge its internal demands, which will strengthen the Chinese economic confidence and play a driving role in promoting its economic development.

\section{Enterprise brand}

Quality is the life of an enterprise, and brand is the eye of an enterprise. Today when the globalization tendency is pricking up, Olympics is a huge incubator of an enterprise brand. Elevation of enterprise brand in the international competition in virtue of Olympics has become an important marketing strategy for the self-development of an enterprise. "According to the statistics, if an enterprise intends to upgrade its brand recognition in the world, it needs an advertising expense worth of 0.1 billion USD for each $1 \%$ of its improvement, while the same amount of expense can upgrade its recognition up to $3 \%$ if it is used to sponsor large-scale sports contests, such as Olympics." ${ }^{[8]}$ Olympic economy has become an overwhelming economic phenomenon in the global economic development of recent 30 years. Olympic economy is brand economy, which could build up a set of well-known products and enterprise brands if perfectly operated. Olympic economy is also brand economy, and through perfect running, quite lots of well-known product and enterprise brands can be built up. An enterprise can deeply excavate the connotation of "Swifter, Higher Stronger" of the Olympics according to its operational field and its brand features, find out reasonable explanation for its brand, and manifest its power and credit. Coca Cola, GE, Kodak, McDonald's, Panasonic and Samsung are all typical cases. Especially for Samsung, it has been the cooperative partner of the International Olympic Committee since Seoul Olympics in 1988, and has been for a succession of six years. In the recent 20 years, Samsung has finished its span from "South Korean Samsung" to "International Samsung", and has been the global brand in digital electronics and home appliances.

Within the 30 years since the reform and opening up, a batch of large-sized enterprises has emerged in China which could be accounted into the World Top 500. However, the international popularity and international brands of these enterprises still have a long way to go compared with those of Coca Cola and Samsung. China has made full use of the unprecedented opportunity of Beijing Olympics to shape its brand value and status. The enterprise brand value marketed in the Beijing Olympics is as follows:

\subsection{Independence}

Enterprise brand can be said to be an unity of credit, competence and performance. Credit is accumulation of an enterprise's long-term credibility, competence includes such external factors as products, service, and quality, etc, while performance refers to propaganda of power and credit. At the time when consumers of the whole world are paying attention to the Olympic contest, it is inevitable that they acquire information of enterprises, brands and products in between. During the year preceding the Olympics, the year of Olympics, and the year following, Chinese enterprises have designed marketing combination centering on Olympics, and have effectively marketed their brands, which not only helps to elevate their total sale amount, but is likely to gain marks for their brand value. During the Olympics, Chinese enterprises broke through independent innovation value for their brand marketing. For instance, the president of Legend Holdings Ltd., Liu Chuanzhi believes that, the purpose of their sponsoring the Olympics is to make full use of this opportunity to manifest technology of Legend. Legend manifesting of technical innovation has attainted its perfection, which is indicated in the fact that, merely design and making of the "auspicious cloud torch" has broken through tens of independent innovation technologies, and has created the history of "auspicious cloud torch" inflaming without extinction on Mount Everest.

\subsection{Quality}

With the concept of green Olympics gradually penetrating into people's heart, requirement for environmental protection has been the important precondition for purchase of Olympic facilities. Air-conditioners used to be one of "chief criminals" in damaging the global ozone layer, of which Haier made best use of the advantages and avoided the disadvantages, and successfully invented the best quality of energy saving, environmental protection and service. It is by replacement of the "environmental protection and cooling catalyst" with technical quality that Haier has won actual scores for its brand value. Data of the top 100 enterprises in electronics information issued by Ministry of Information Industry in 2006 indicated that, in 2006, the export amount of Haier Group attained 10.73 billion RMB. Currently, several Chinese home appliance enterprises have had conditions for entering the international market. The quality 
strategy by Haier is a wonderful lesson for how to enter the international market and how to realize rapid development. Meanwhile, in respects of fulfilling responsibilities of the social Olympic citizens, and transmitting Olympic spirit and culture, etc, Haier Group has realized the target of mutual stimulation of the brand popularity, reputation and Olympic transmission.

\subsection{Value}

If an enterprise could fulfill strict requirements of International Olympic Committee for its cooperative partner, and become the partner of the Olympics, this would have direct and strong stimulative effect on the elevation of its value chain and on the distillation of its value chain. "To fulfill requirements of the Olympics" has become the unified standard of an enterprise on each aspect of its value chain, which is helpful for an enterprise to distribute more outstanding suppliers, sellers and other service agents, and to increase the overall advantages and competence of its value chain. For instance, in the case of Tsingtao Beer, its combination with the Olympics is firstly indicated in their strategic inosculation. Tsingtao Beer is an international brand per se, and Olympics is also an international contest, so inosculation is satisfied in their strategies. The slogan of Beijing Olympics is "One World, One Dream", while that of Tsingtao Beer is "Passion, dreams \& success", in which their brand relevancy is quite obvious. Whether for manufacturing enterprises or for service enterprises, internationalization doesn't merely refer to that of its products, or to that of the enterprise per se, but an internationalization of all its partners in its value chain, especially its upper suppliers.

As for Chinese enterprises, both sports marketing and Olympic marketing are a new subject. Therefore, most of the time, our enterprises are lacking in strategic ideas and even eager for quick success and instant benefit. For example, a good many enterprises consider Olympics a perfect opportunity to expand itself, and make great effort in advertisement propaganda and market promotion, but normally ignores basic requirements of Olympic spirit, not having much more positive interaction with consumers, and with relative groups in the community, the city and the national government. Hence, they can only gain superficially --- with popularity, but without reputation, more returns and persistence of their brands. Facing the significant issue of Olympics, many enterprises reveal disadvantages of commercial experiences and management skills compared with brand marketing of Coca Cola in that, boldness and negligence has become the largest disadvantage in their operation during the Olympics. For example, Sanlu toxic baby milk incident which took place after the Beijing Olympics has affected adversely Yili, and seriously damaged its original strength, which was a painful lesson. Still, Chinese enterprises should strengthen their sport marketing in terms of values, social responsibility, Olympic citizens' life realm and everlasting spirit, etc,. All this tells that, there is a long way to go for Chinese enterprises to realize their internationalized brand strategy.

\section{Citizen brand}

Citizen brand refers to manifestation of the national citizen's quality. National quality also refers to competence and makings of all the national citizens in the social activities. It is extremely significant to a country, since it is related to the national destiny and future. Beijing Olympics is also a window to manifest spiritual civilization of the present Chinese people, and is a hard-won stage for displaying the national quality. In recent years, western industrialized countries have not reached an agreement upon praise and satirization of Chinese people. Their general comments on China are no more than that, Chinese people created unprecedented and gorgeous civilization, but they don't possess any quality of modern civilization. Chinese superiors lay great importance to improvement of national quality, and they firmly believed that the quality of Beijing citizens were decisive in success of the Olympics even when the Olympics was successfully bidded for. In cooperation with relative departments and through vigorous mobilization of several years, the Beijing Olympic Committee made propaganda extensively, offered education and training. In return, during the Olympics, Beijing citizens and volunteers displayed new standards of national quality development, and left positive impression upon guests from all over the world. The national quality brand value displayed during the Beijing Olympics was as follows:

\subsection{Civilization}

"Welcomes the Olympics, stressing civilization, a new trend, --- I have been involved in, my dedication, my happiness". From successful application for the Beijing Olympics until its coming, civilians in Beijing have been practiced this slogan with their actions. Not only in Beijing, this activity of "stressing civilization, a new trend" has spread all over the whole China. A lot of cities and towns, schools, organs, and enterprises printed and distributed handbooks of civilization and etiquette, and propagandized various etiquette criteria. To realize politeness, to learn politeness, and to put it into practice has become a vogue in the Chinese citizens. Olympics not only provides a platform to manifest Beijing and China, but an opportunity to supervise and promote the national civilization and politeness. With the notion of humanism Olympics, and the gradual improvement of city functions, civilization quality of citizens, their spiritual outlook, and the social modern civilization degree all get further improved. We warmly welcome guests from all around the world with politeness, and in return, we get respect from them. Such a smile also enables volunteers everywhere to be beautiful scenery of the Beijing Olympics. Most of the volunteers are young people born in "the late 1980s", and 
their loveliness, smile and diligence is the best name card for displaying China's image, and for exhibiting China's future and brightness. In Rogge's viewpoint, "Beijing Olympics has elevated consciousness of environmental protection in Beijing people and people of the whole China." All sorts of environmental protection education and propaganda activities unfolded all over the country have improved the public environmental consciousness gradually. Such voluntary environmental protection activities as rubbish assortment, planting of carbonneutral forest, and one fewer day of driving have been more and more overspread, and have been a brand-new highlight of the green Olympics, environmental protection notion gradually penetrating into inner heart of each national citizen.

\subsection{Passion}

Altogether, the largest volunteer team is constituted by 100,000 games volunteers, 400,000 city volunteers, 1 million social volunteers, 200,000 cheering squad members, and 550 city service stations. Under the impelling of the slogan "I have been involved in, my dedication, my happiness", they provide excellent service all the way with their hundredfold efforts and passion. In the whole city, a perfect atmosphere emerged with smile as the center. It was devotion and earnest efforts by thousands of people that fulfilled a glory new to the whole world. 5000 years' civilization and friendliness of the Chinese nation gets thorough manifestation. From the 380 medal presentation ritual girls to thousands of Olympic volunteers, and from smiling cab drivers to smiling ordinary people everywhere, a shocking power of most friendly smile and etiquette country with ancient civilization was, all without exception, displayed to the world. What should be particularly mentioned, in face with Wenchuan earthquake, Chinese people combined the great earthquake relief work spirit of "hearts together, dreams come true, face a difficulty" with the Olympic spirit of "Challenge the limit and indomitable struggle" with their indomitable spirit and strong will, and brought much more brilliance to the Beijing Olympics.

\subsection{Smile}

Dedication is the core of voluntary spirit. The grand global ceremony held by the 1.3 billion hosts was shocking not only owing to its magnificent vigor, but more to the enjoyable sea gathered from minor dedication. In the upsurge of "Welcomes the Olympics, stressing civilization, a new trend", each face was filled with warm smile. On most occasions, Chinese audience could cheer up for all athletes with an attitude of appreciation and encouragement. And in some contest fields, Chinese audience even cheered up for struggling losers with no identification of nationalities, hosts and guests, for those players who insisted on competition even with injury, and for those falling off from sports facilities due to rough handling in adventurous high-altitude movements. All these civilized and friendly behaviors indicated the worshipful humanity and gracious spiritual pursuit, highly appraised by athletes from many countries and judges of the Olympic Committee.

The Beijing Olympic spirit helps improvement of Chinese people's quality, figuring of their concepts, and transition of their life style, and helps all-around development of the contemporary Chinese people and their modernization. Chinese people in the eyes of people all over the world, not only inherit the traditional moral and cultural attainment, but also possess modern open civilization bearing. An upgoing, firm and confident spiritual feature of Chinese people has won respect from the entire world. However, if we really take the root of the civilization habit and perfect life style promoted during the Olympics into China, and "enable them to be component of the national life style", there would be lots of difficult tasks to overcome and a long way to go.

By and large, "We all live in an era of attention economy". The Beijing Olympics has attracted attention of the whole world, and has left us abundant brand value heritage. We can study and excavate the brand value of Beijing Olympics from different perspectives. However, among all brands, the national brand is the most particular one and is a central brand. All other brands, such as city brand, enterprise brand and citizen brand, are all organic elements of the national brand, which support the national brand, and meanwhile, the national brand offers the most fundamental and directing support for the other three brands. Owing to the Beijing Olympics, the national brand gets upgraded, which would necessarily play an overall promotive role in manifestation of the city enchantment, marketing of enterprise brand, and improvement of the national citizens.

\section{References}

Dong, Xiaoying \& Peng, Siqing. (2008). Opportunities and Challenges for Elevation of National Image. Science and Technology Review, (15), 99.

Huang, Wei. (2008). Not to Judge Success and Failure on Profit and Loss. China Investment, (8), 53.

Leo van den Berg Erik Braun Alexander. (2006). Sports and City Marketing, translated by Shen, Tiyan et al. Beijing: People Press, 16.

Liu, Jinan. (2002). International Communication and National Image ---New Perspective of International Relations. Beijing: Communication University of China Press, 263.

Lu, Taihong \& Luo, Qiming. (2003). Sports Marketing, Olympic Book, World Cup Book. Sichuan People's Publishing 
House.

Ma, Rong. (2008). The Most Important: Transition of Thinking Mode. People s Tribune, (9) 19B, or 234.

Talk by Hu, Jintao in his interview with Chinese and foreign journalists. (2008). People Network ---People Daily, 00:00, August 2.

ThomasH.Davenport, Jogn. Beck. (2002). Attention Economy, translated by Xie, Bofeng, et al. Beijing: China Citic Press, 2.

Wu, Jianmin. (2008). Profound Influences of Beijing Olympic Games. China Today, (9), 35. 